\title{
Late degradation tissue response to poly(L-lactide) bone plates and screws
}

\author{
J.E. Bergsma, W.C. de Bruijn*, F.R. Rozema, R.R.M. Bos and G. Boering \\ Department of Oral and Maxillofacial Surgery, University Hospital Groningen, PO Box 30.001, 9700 RB Groningen, \\ The Netherlands; "AEM Unit, Clinical Pathological Institute I, Erasmus University of Rotterdam, The Netherlands
}

\begin{abstract}
Patients with fractures of the zygomatic bone were treated with high molecular weight poly(L-lactic) acid (PLLA) bone plates and screws. Three years after implantation four patients returned to our department with a swelling at the site of implantation. At the recall of the remaining patients we found an identical type of swelling after the same implantation period. To investigate the nature of the tissue reaction, eight patients were reoperated for the removal of the swelling. The implantation period of the PLLA material varied from 3.3 to 5.7 years. Microscopic evaluation and molecular weight measurements were performed. The excised material showed remnants of degraded PLLA material surrounded by a dense fibrous capsule. Ultrastructural investigation showed crystal-like PLLA material internalized by various cells. The results of this investigation suggest that the PLLA material slowly degrades into particles with a high crystallinity. The intra- and extracellular degradation rate of these particles is very low. After 5.7 years of implantation, these particles were still not fully resorbed. Biomaterials (1995), 16 (1), 25-31
\end{abstract}

Keywords: Poly (L-lactide), biodegradation, tissue response, enzyme activity

Received 28 November 1993; accepted 25 April 1994

Metallic bone plates and screws are commonly used in oral and maxillofacial surgery for internal fracture fixation. Although good fracture healing is obtained, the disadvantages of metallic plates and screws are the possibility of bone atrophy due to stress-shielding and the obligation to remove these devices in a second operation $^{1-3}$. Bone plates and screws made of a biodegradable material are considered to be a good alternative for metallic ones. The main advantage of biodegradable plates and screws is that they lose their mechanical properties due to degradation so that loads are gradually retransferred to the bone, preventing stress-shielding of the healed bone. Moreover, if the material fully degrades, a reoperation for the removal of the plate and screws can be avoided ${ }^{4-6}$.

Because of these advantages, biodegradable polyesters such as poly(L-lactide) or polyglycolide have been studied extensively during the last two decades. These biodegradable polyesters have been used as internal fixation devices in the shape of rods, screws and bone plates ${ }^{7-9}$.

At our department high molecular weight aspolymerized poly(L-lactide) (PLLA) has been a material of special interest because of its good mechanical properties $^{10-12}$. To gain insight into the mechanical behaviour during degradation, PLLA was used for fracture fixation of the mandible of $\operatorname{dogs}^{13}$ and sheep ${ }^{14}$, and for orbital floor reconstructions in goats ${ }^{15}$. In all cases the PLLA plates gave sufficient stability to enable undisturbed fracture healing ${ }^{13-15}$.

Correspondence to Dr J.E. Bergsma.
In a study on rats the biocompatibility and degradation characteristics of PLLA were investigated ${ }^{16}$. The histological reaction to the implanted PLLA material was very mild: only a slight foreign body reaction was observed after a follow-up of 2.8 years. The implanted PLLA material showed a rapid decrease of molecular weight but only a small mass loss.

Total resorption of the PLLA material was not observed in this study on rats, but was estimated to be about 3.5 years.

Based on the pusitive results in animal studies, a limited investigation in humans was set up. PLLA bone plates and screws were used for the fixation of unstable zygomatic fractures ${ }^{17}$. Three years after implantation, four patients returned to our department spontaneously because of a swelling at the site of implantation ${ }^{18}$. Another five patients were recalled and all showed identical swellings.

The aim of this study is to characterize the remainder of the PLLA material after an implantation period of 3.3 and 5.7 years, in order to gain an insight to the nature and course of the swelling at a light microscopical, ultrastructural and cytochemical level.

\section{MATERIALS AND METHODS}

\section{Patients}

From 1986 to 1988 , ten patients (mean age $39.6 \mathrm{yr}$; range $20.2-61.8 \mathrm{yr}$ ) with solitary displaced unstable fractures of the zygoma were treated with high molecu- 
lar weight as-polymerized poly(L-lactide) bone plates and screws $\left(\vec{M}_{\mathrm{v}}=1 \times 10^{6}\right.$, calculated using the formula $[\eta]=5.45 \times 10^{4} \bar{M}_{\mathrm{v}}^{0.73} ;$ and $\bar{M}_{\mathrm{n}}=7.6 \times 10^{5}$, calculated using the formula $[\eta]=3.25 \times 10^{4} \bar{M}_{\mathrm{n}}^{0.77}$ ). Unfortunately one patient died of a cerebrovascular accident one year after implantation. Three years after implantation, four out of nine patients returned to our department at their own initiative because of a painless swelling at the site of implantation ${ }^{19}$. At a recall, the remaining five patients showed a similar swelling. In a period of two years, seven patients agreed to have a reoperation for the exploration of the area of swelling. The postoperative implantation period varied from 3 years 4 months to 5 years 8 months. The reoperation was performed under general anaesthesia. The tissue in the area of the swelling was excised via an incision laterally in the eyebrow. Samples of the screw-holes were taken by trephination of the bone.

\section{Characterization of the degraded PLLA}

From a part of the excised tissue the remainder of the PLLA material was mechanically removed and was subsequently treated with trypsin $2.5 \%$ in Hank's balanced salt solution and collagenase la for the removal of organic components. The PLLA particles were then dried under vacuum for $17 \mathrm{~h}$ at $10^{-3}$ bar to constant weight. Nuclear magnetic resonance (NMR) measurements for the determination of the molecular weight were carried out on a Varian $300 \mathrm{NMR}$ spectrometer. The ${ }^{1} \mathrm{H}$ NMR spectra were obtained from polymer solutions in deuterated chloroform in $5 \mathrm{~mm}$ tubes. For scanning electron microscopy (SEM) analysis, dricd PLLA particles were gold-palladium sputter-coated and photographed in a DS 130 (ISI) scanning electron microscope.

\section{Histological procedures}

Slices $2 \mathrm{~mm}$ thick were cut perpendicular to the long axis of the excised tissue mass and fixed in $2 \% \mathrm{v} / \mathrm{v}$ glutaraldehyde in $0.1 \mathrm{M}$ phosphate buffer of $\mathrm{pH} 7.4$ for at least $48 \mathrm{~h}$ at $4{ }^{\circ} \mathrm{C}$. For light microscopy, sections were dehydrated in graded series of ethanol. The sections were embedded in glycol-methacrylate, polymerized for $24 \mathrm{~h}$ at $-20^{\circ} \mathrm{C}$. Sections of $2 \mu \mathrm{m}$ were made (Jung microtome 1140/autocut), which were stained with toluidine blue and basic fuchsin. For electron microscopy, postfixation was performed with 1 wt \% $\mathrm{OsO}_{4}$ to which $\mathrm{K}_{4} \mathrm{Fe}(\mathrm{CN})_{6} .3 \mathrm{H}_{2} \mathrm{O}$ was added to a final concentration of $0.05 \mathrm{M}$. Subsequently, the material was dehydrated in series of $70,80,90$ and $100 \%$ acetone. The material was embedded in LX 112 epoxy resin and polymerized for $24 \mathrm{~h}$ at $60^{\circ} \mathrm{C}$. Based on light microscopic observations, ultrathin $70 \mathrm{~nm}$ sections were acquired at selected sites, around the screw-head and at the periphery of the bone plate. These ultrathin sections were stained with uranyl acetate/lead citrate. For transmission electron microscopy a Zeiss EM 902 was used, operating at $80 \mathrm{kV}$.

\section{Histochemical procedures}

To investigate possible enzymatic activity towards the membrane-bound PLLA conglomerates, cytochemical reactions were performed on the material implanted for 5.7 years. For the demonstration of acid phosphatase and alkaline phosphatase, aldehyde-fixed tissue was used. For the demonstration of lactate dehydrogenase (LDH), fresh $5 \mathrm{~mm}$ tissue slices were quickly frozen at $-80^{\circ} \mathrm{C}$. Perpendicular to the bone plate axis, sections were cut of $50 \mu \mathrm{m}$ thickness in a cryostate microtome at $-28^{\circ} \mathrm{C}$. The histochemical methods for the enzymes investigated are summarized in Table 1.

\section{RESULTS}

\section{Material characterization}

The mean number molecular weight $\left(\bar{M}_{\mathrm{n}}\right)$ of the PLLA particles as determined by NMR was respectively 5600 and 5400 for the 3.3 and 5.7 years implanted PLLA. The plates and screws were machined out of a block of as-polymerized with an $\bar{M}_{\mathrm{n}}$ of $7.6 \times 10^{5}$.

Ultrastructural SEM examination of the 3.3 years material revealed particles varying in size from 1 to $1500 \mu \mathrm{m}$ (Figure 1). The larger PLLA fragments showed numerous whitish cracks. Many smaller particles seemed to be adhered to the surface. Higher magnification of a particle showed an irregular surface structure. The SEM appearance of the material implanted for 5.7 years showed at some parts a microporous structure, again with many smaller particles attached to it. The mean particle size seemed to be smaller compared with those of the 3.3 years implanted material.

\section{Histological analysis}

The material excised after an implantation period of 3.3 years showed a firm consistency and the contours of some of the screw-heads could still be seen. Light

Table 1 Histochemical methods for the enzymes investigated.

\begin{tabular}{|c|c|c|c|c|}
\hline Enzyme & Substrate, cofactors, coupling agent & Buffer and $\mathrm{pH}$ & Incubation (time, temp) & Reference \\
\hline $\begin{array}{l}\text { Acid } \\
\text { phosphatase }\end{array}$ & $\begin{array}{l}1.5 \mathrm{mg} \mathrm{ml}^{-1} \text { Sodium- } \beta \text {-glycerophosphate } \\
1 \mathrm{~mm} \text { Cerium chloride }\end{array}$ & $\begin{array}{l}0.08 \mathrm{M} \text { Tris-maleate } \\
\mathrm{pH} 5.0\end{array}$ & $30 \mathrm{~min}, 37^{\circ} \mathrm{C}$ & Hulstaert et al. ${ }^{20}$ \\
\hline $\begin{array}{l}\text { Alkaline } \\
\text { phosphatase }\end{array}$ & $\begin{array}{l}1.5 \mathrm{mg} \mathrm{ml} \mathrm{ml}^{-1} \text { Sodium- } \beta \text {-glycerophosphate } \\
1 \mathrm{~mm} \text { Cerium chloride } \\
4 \mathrm{~mm} \text { Magnesium chloride }\end{array}$ & $\begin{array}{l}0.1 \mathrm{M} \text { Tris-maleate } \\
\mathrm{pH} 9.2\end{array}$ & $30 \mathrm{~min}, 37^{\circ} \mathrm{C}$ & Hulstaert et al. ${ }^{20}$ \\
\hline $\begin{array}{l}\text { Lactate } \\
\text { dehydrogenase } \\
(\mathrm{LOH})\end{array}$ & $\begin{array}{l}2.5 \mathrm{mg} \mathrm{ml}^{-1} \text { Lactic acid lithium salt } \\
0.05 \mathrm{M} \mathrm{potassium} \mathrm{ferricyanide} \\
0.5 \mathrm{mg} \mathrm{m}^{1} \mathrm{NAO}^{+}\end{array}$ & $\begin{array}{l}0.1 \mathrm{M} \text { Phosphate } \\
\text { buffer } \\
\text { pH } 7.2\end{array}$ & $60 \mathrm{~min}, 37^{\circ} \mathrm{C}$ & Hanker et al. ${ }^{21}$ \\
\hline
\end{tabular}




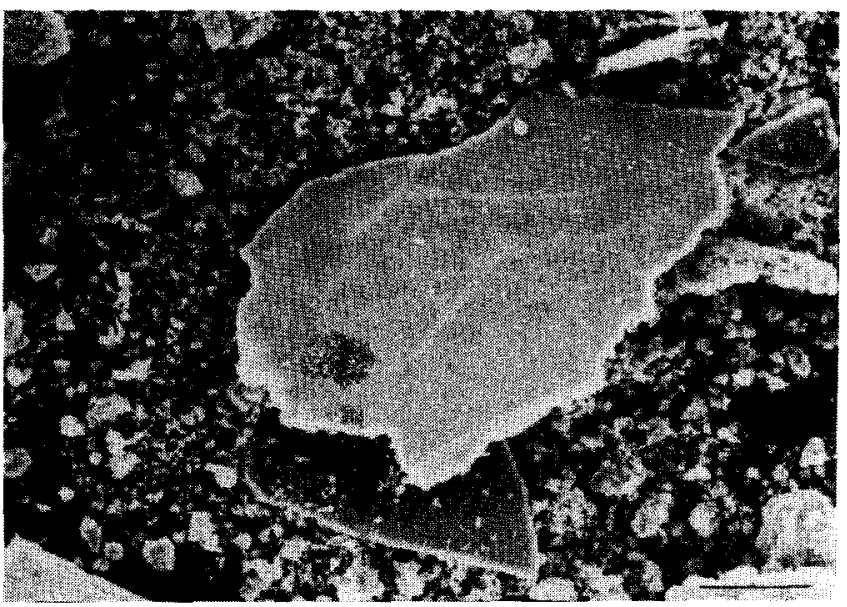

Figure 1 Scanning electron micrograph of the remnants of the 3.3 year implanted poly(L-lactic) acid material (scale bar $=500 \mu \mathrm{m}, 40 \mathrm{kV})$.

microscopic analysis of this material revealed a fibrous tissue capsule that enveloped large areas of foreign body material. Under crossed Nicol prisms the areas with the foreign body material were brilliantly birefringent representing the PLLA material. At low magnification of a section through a screw-head and bone plate, areas with densely packed birefringent PLLA-like material were seen. These areas were separated by fibrous tissue that varied in thickness throughout the section. In parts where the capsule measured about $150 \mu \mathrm{m}$, a sharp boundary between the closely packed PLLA material and the fibrous tissue was seen (Figure 2a). Here, no birefringent material was situated in the capsule. These parts of the capsule, with a sharp interface PLLA/fibrous tissue, were investigated ultrastructurally. Transmission electron microscopy (TEM) revealed densely packed foreign body material with a lamellar or needle-like structure in close contact with orientated bundles of collagen fibres (Figure $2 b$ ). These non-electron dense needle-like particles represented the PLLA material. Between these fibres long slender cells were present that could be characterized on morphological grounds to be fibrocytes. Virtually no other cells like macrophages, foreign body giant cells or lymphocytes were seen in this area. No PLLA was situated in the cytoplasm of cells or in the extracellular space between the collagen fibres.

Light microscopically it was observed that in other parts of the section the fibrous tissue spread out, and PLLA particles were seen between bundles of collagen and cells. In these parts the cells most frequently present were long slender fibrocytes. Only a small number of macrophages or lymphocytes were seen. Electron microscopy revealed that fibrocytes possessed well developed organelles like rough endoplasmic reticulum and golgi apparatus. In a number of cells with internalized PLLA, a clear deposition of glycogen around phagosomes was seen. In the plasma membranes of the fibrocytes a high number of endocytotic vesicles was observed. Intracellularly, fibrocytes showed a profuse amount of PLLA material which was mostly packed in membrane-bound vacuoles which could be described as phagosomes (Figure 3). Fusion

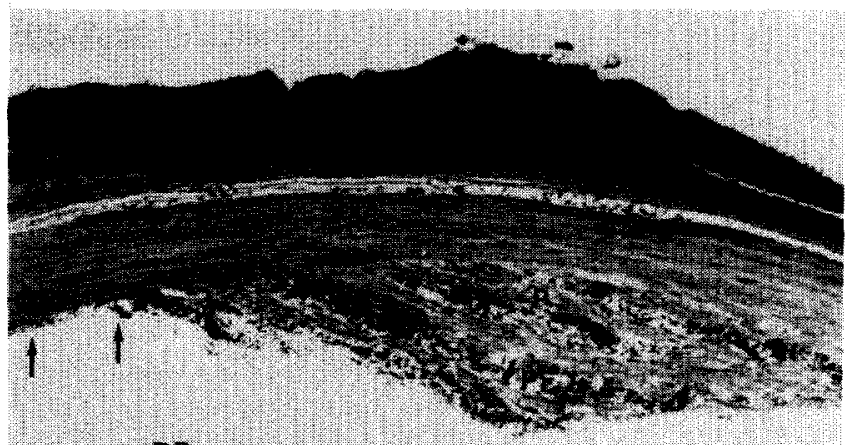

$\mathrm{mp}$

a

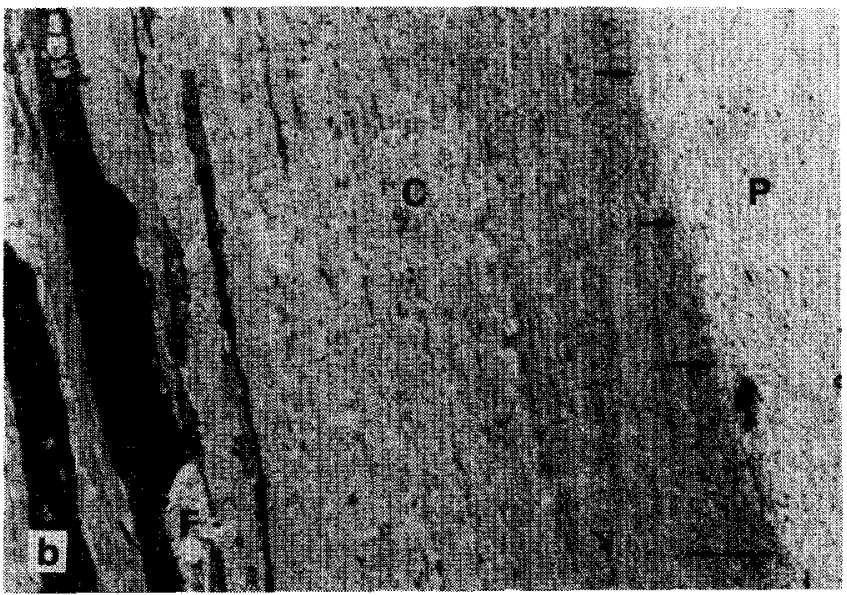

Figure 2 a, Micrograph of the 3.3 year implanted material, taken under crossed Nicols prisms, of the fibrous capsule with centrally removed poly(L-lactic) acid (PLLA) particles (RP). The arrows indicate a part of the capsule with a sharp interface PLLA/fibrous tissue. In other parts birefringent PLLA particles (P) were situated between bundles of collagen $(C)$ (original magnification $\times 40$ ). b. Transmission electron microscopic (TEM) photograph of the 3.3 year implanted material. The arrows indicate a sharp interface of densely packed needle-like PLLA material (P) and orientated bundles of collagen fibres (C). These orientated bundles of collagen are intermingled with fibrocytic (F) cells (scale bar $=2.5 \mu \mathrm{m}$ ).

of a lyosome with a packed vacuole forming a phagolysosome was observed only infrequently. In a small number of fibrocytes the incorporated PLLA particles were also situated apparently freely in the cytoplasm. The cells with incorporated PLLA material had swollen parts of endoplasmic reticulum, which could indicate an increased protein synthesis, and swollen mitochondria that lacked the cristae suggesting physiological damage. Although PLLA particles were seen between collagen fibres and cells, the bulk of the PLLA material was still situated extracellularly and was not interlaced with collagen fibres and cells.

Macroscopical investigation of the 5.7 years material showed a tissue mass which lacked the firm consistency of the 3.3 years material. The contours of some of the screw-heads were still visible. Microscopic examination at low magnification showed a sharp outline of a thin fibrous capsule. At the peripheral 


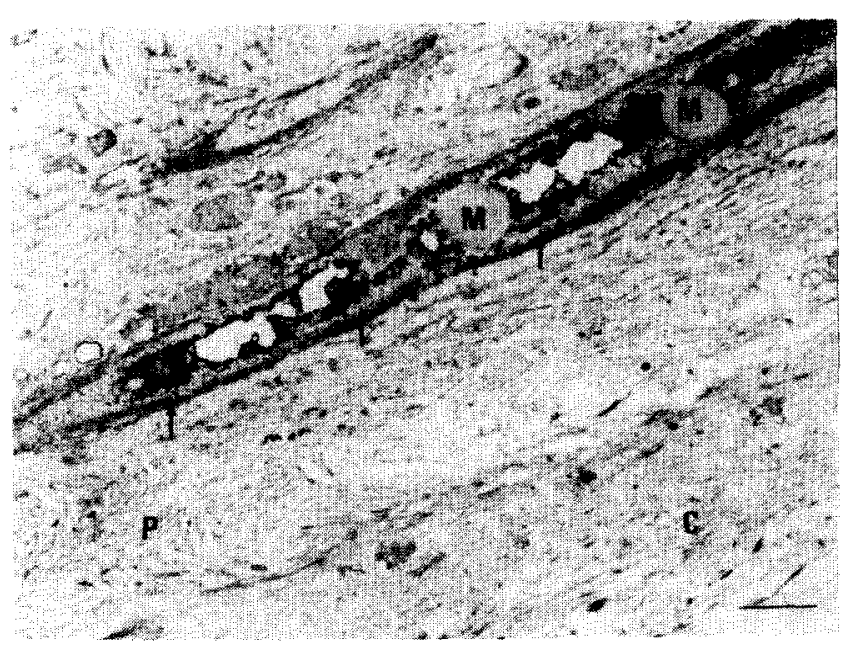

Figure 3 Transmission electron micrograph of a fibrocyte with glycogen accumulation (arrows) around phagosomes and swollen mitochondria (M). The cell is situated in fields of poly (L-lactic) acid particles $(P)$ and sheets of collagen (C) (scale bar $=1.7 \mu \mathrm{m})$.

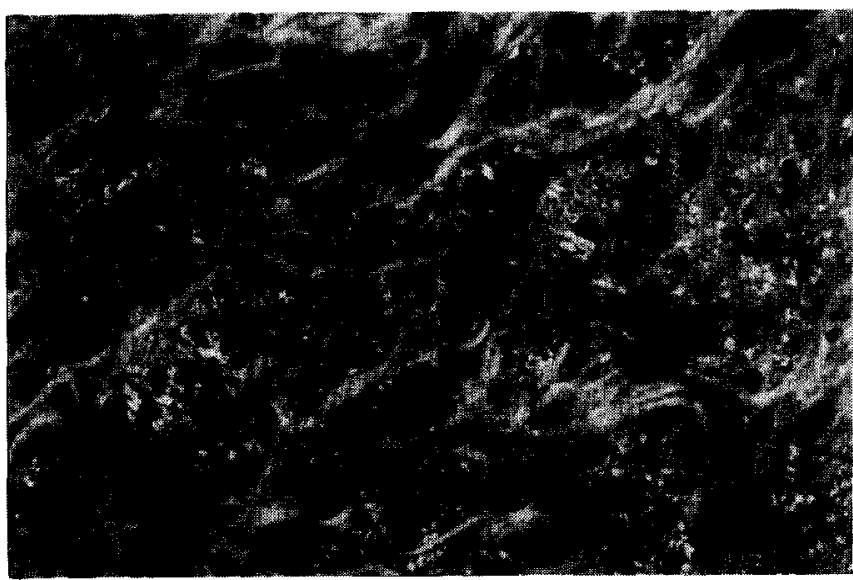

Figure 4 Birefringent poly(L-lactic) acid particles intracellularly in foamy macrophages (arrows), 5.7 years after implantation (original magnification $\times 250$, taken under crossed Nicol prisms).

parts of the screw-head region, blood capillaries, nerve fibres and fat deposition were observed. More centrally in the screw-head region, randomly orientated bundles of collagen were seen amidst various kinds of cells. In this section, no large areas of densely packed extracellular PLLA particles were found. A section through the bone plate showed large fields of cells with intracellularly positioned birefringent PLLA material (Figure 4). This section was composed of mainly foamy macrophages surrounded by fibrous tissue.

Electron microscopic observations revealed that most of the PLLA material was situated intracellularly in various cells. These phagocytizing cells formed clusters that were encapsulated by mature and randomly orientated bundles of collagen. The number of elongated fibrocytic cells with internalized PLL $\Lambda$ material had diminished as compared to the situation after 3.3 years. The number of macrophages and foreign body giant cells had increased and represented the

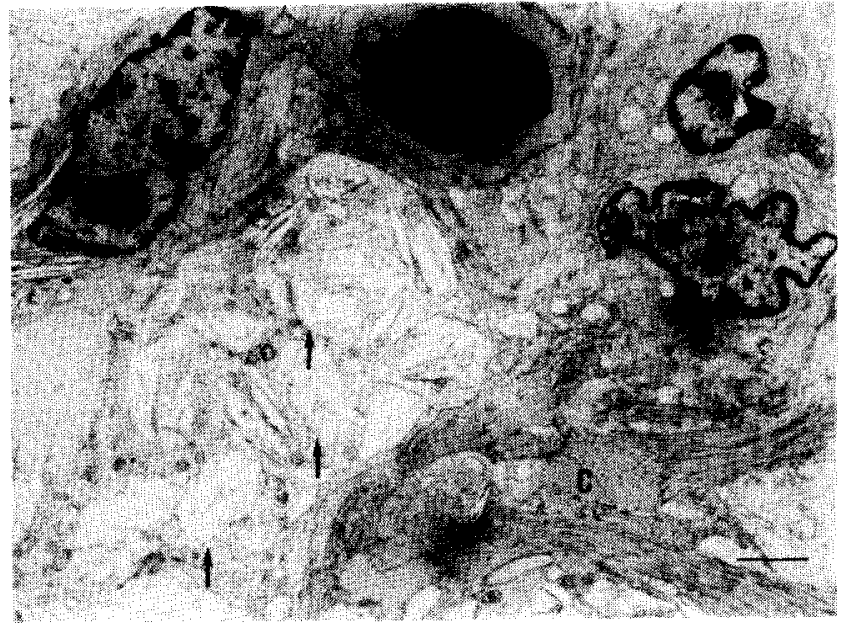

Figure 5 Membrane-bound conglomerates of poly (L-lactic) acid particles (arrows) described as phagosomes in the cytoplasm of a phagocytic cell. All cells are embedded in a mature fibrous capsule (C) (scale bar $=2.5 \mu \mathrm{m}$ ).

major phagocytizing cellular component. In these cells the PLLA particles were no longer found freely in the cytoplasm, but entirely as membrane-bound conglomerates (Figure 5). The morphology of phagocytizing cells showed minimal signs of cell damage. The cytoplasmir organelles, such as mitochondria and rough endoplasmic reticulum, were of normal appearance.

A sample of trephined bone was obtained from a patient after an implantation period of 5.7 years. The tapped screw-holes were still visible and not fully filled in with cortical bone. On a section perpendicular to the long axis of the screw-hold, birefringent PLLA particles were still densely packed in the shape of the screw-thread. These densely PLLA particles were not interlaced with collagen fibres or cells. A fibrous capsule was situated between cortical bone and the bulk of the PLLA particles and had at some parts spread out into the lacunae of the cortical bone (Figure 6). Fields of PLLA particles were seen up to $0.5 \mathrm{~mm}$ from the original implant site showing birefringent PLLA material between sheets of collagen and in various cells. Ultrastructural investigation showed that the PLLA material had the same lamellar or needlelike structure as observed in the soft tissue.

As an indicator of cell damage or high lactic acid concentrations, possibly released from the PLLA particles, the presence of lactate dehydrogenase (LDH) was investigated. The presence of LDH in mitochondria was demonstrated by a cytochemical reaction: Hatchett's brown depositions amplified by treatment with 3,3'-diaminobenzidine (DAB) and osmication were seen in close relation to the cristae, the intracristate spaces and the intermembrane spaces of mitochondria (Figure 7). There was no evidence of LDH-related precipitates in the membrane-bound conglomerates, or in close contact with the PLLA particles; nor were extracellular LDH-related precipitates, possibly released by damaged or lytic cells demonstrated. Control specimens, without nicotinamide adenine dinucleotide (NAD) and/or DAB/osmium showed no Hatchett's brown depositions in mitochondria. Acid phosphatase could be demonstrated in lysosomes in a 


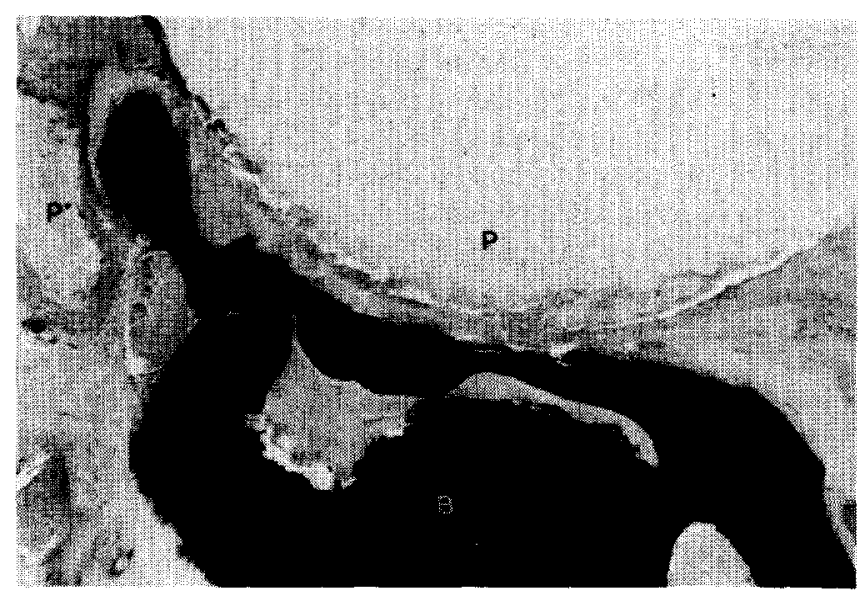

Figure 6 Densely packed poly(L-lactic) acid (PLLA) particles $(P)$ in the shape of the screw-thread surrounded by cortical bone $(B)$. Fields of PLLA particles were seen at some distance of the original implant in the cortical bone $\left(P^{\prime}\right)$ (original magnification $\times 40$ ).

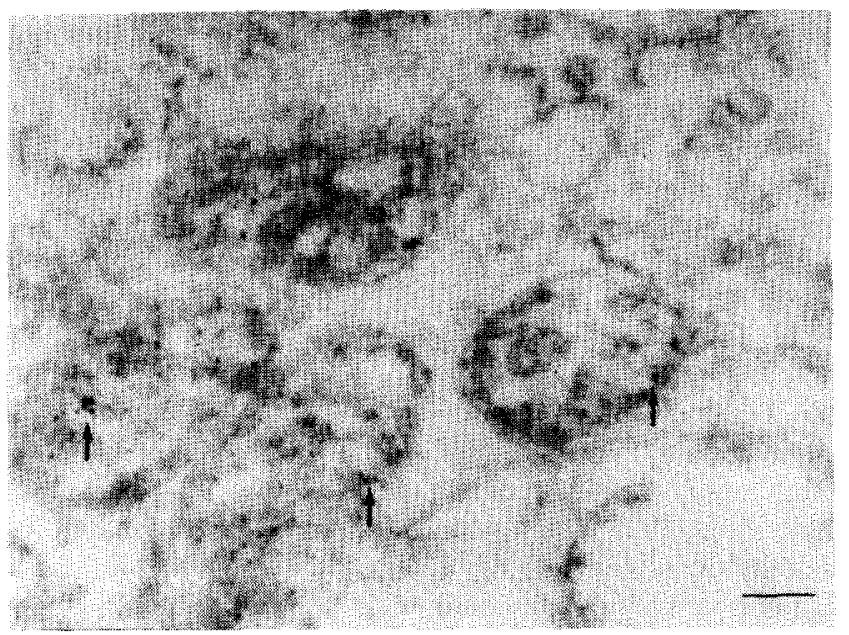

Figure 7 Hatchett's brown depositions amplified by treatment with $3,3^{\prime}$-diaminobenzidine and osmication were seen in close relation to the cristae, the intracristate spaces and the intermembrane spaces of mitochondria (scale bar $=0.25 \mu \mathrm{m}$ ).

limited number of macrophages that had internalized PLLA particles. Some of these lysosones were seen in close contact with the PLLA-bearing phagosomes. Fusion of a primary lysosome and a phagosome forming a phagolysosome was rarely seen.

\section{DISCUSSION}

The total resorption time of as-polymerized PLLA was estimated in previous studies to be 3.5 years ${ }^{15,16}$. The results of this experiment show that the PLLA bone plate and screws, implanted for 3.3 years, had degraded into fragments and disintegrated into particles that have a needle-like structure on TEM. Ultrastructural TEM analysis of the PLLA nuterial with an implantation period of 5.7 years shows a comparable morphology. SEM analysis would suggest that the average particle size of the material implanted for 5.7 years is much smaller. Between 3.3 and 5.7 years the PLLA material degrades from fragments into particles that have a needle-like structure on TEM. Light microscopic observations suggested that the number of PLLA particles that were internalized by cells had increased with longer implantation periods.

The molecular weight, about 5000 , is identical for both implantation periods. Rozema ${ }^{21}$ described that an $\bar{M}_{\mathrm{n}}$ of $\mathbf{5 0 0 0}$ may be a break-even point as a start of relative high disintegration. However, the PLLA particles have a rather high crystallinity ${ }^{21}$ which is probably one of the factors that makes them very stable and not very susceptible to hydrolysis. This may explain the very limited progression of the degradation of PLLA particles in the period from 3.3 to 5.7 years. Substantial mass loss or total resorption had not taken place up to 5.7 years. If a PLLA particle degrades, it is probably in non-detectable oligomers that are washed away with tissue fluids and are not detected in the material analysis. This mechanism may account for the same values of molecular weight and crystallinity for both implantation periods.

The origin of the described swelling is not quite clear. Maybe the swelling is initiated by a gradual disintegration of the PLLA bone plate and screws into fragments. Bergsma et $a .^{18}$ described how during degradation the PLLA plates and screws disintegrate into small fragments which may lead to an increased volume in comparison with the volume of the intact bone plate and screws. In a cross-section of tissue implanted for 3 years, the surface area occupied by the a-cellular PLLA particles was estimated to be $65 \%$ of the total surface area. The remaining $35 \%$ of the cross-section was occupied by the enveloping fibrous capsule. Böstman et $a l^{22}$, in a study with intraosseously placed polyglycolide screws and pins, suggest that an increased osmotic intracavital pressure associated with the degradation of polyglycolide and the resistance of the surrounding tissue may determine the formation of a sinus. The origin of the described swelling may possibly be explained by a combination of factors such as the disintegration of the PLLA material into small particles, and an increased osmotic pressure caused by these fragments and the, compared to bone, low resistance of the subcutaneous tissue.

Another mechanism that may induce or maintain the swelling is given by Fornasier et $a^{23}{ }^{23}$, who described a correlation between the presence of birefringent polyethylene particles, the density of histiocytes and the thickness of a fibrohistiocytic membrane all of which showed an increase with time. A section obtained from the material with an implantation period of 5.7 years consists of a thin fibrous capsule and sheets of collagen interlaced with various cells. In contrast to the material that was implanted for 3.3 years, scarcely any PLLA material can be found in the extracellular space. The majority of the PLLA crystals has been internalized by phagocytizing cells in membrane-bound vacuoles. These results may lead to the conclusion that with longer implantation periods there is a gradual shift of PLLA parlicles from extra- to intracellular in phagocytic cells that are imbedded in a fibrous matrix. The presence of macrophages and fibrocytes in response to the PLLA particles can be 
expected since macrophages are known to phagocytize and remove foreign body material. As a response to internalization of the foreign body material macrophages can activate and attract fibroblast-like cells.

The extracellular degradation of the PLLA particles is probably a hydrolytic process. However, phagocytizing cells, especially macrophages, can release a number of lysosomal hydrolytic enzymes that may influence the degradation. If this is the case then an increased concentration of the lysosome guide enzyme, acid phosphatase, would be expected. Acid phosphatase is present in all lysosomes and its easy identification makes it an excellent marker. In the tissue with implantation periods of 5.7 years the presence of acid phosphatase was demonstrated, although not in abundance.

Another enzyme that has been studied is lactic dehydrogenase (LDH). LDH converts lactic acid into pyruvate that can be metabolized in the citric acid cycle. If a substantial amount of intracellular PLLA particles degrades into lactic acid an increase might be expected. Again, the presence of enzyme-related precipitates were demonstrated but not in large amounts. Although a very limited number of enzymes were investigated these results may lead to the conclusion that the PLLA particles are eventually all internalized by phagocytizing cells that cannot actively degrade the PLLA particles. Hydrolysis is probably the only degradation mechanism and the highly crystalline particles seem to degrade very slowly. This implies that there is a long lasting presence of intracellular PLLA particles or that the particles are egested into the extracellular space because the cell cannol actively degrade the particles. Indigestible foreign body particles may cause a continuous attraction of macrophages that may again phagocytize the PLLA particles and thus repeat the intracellular cycle.

Based on the literature on silicone implants another possibility may be that PLLA particles, or macrophages with PLLA particles, migrate to nodal tissue from the implant site ${ }^{24}$. In this study no lymph nodes were excised, but perhaps in future studies the pussibility of migration of PLLA particles to lymph nodes should be investigated.

In the orthopaedic literature many studies have been published about aseptic loosening of prosthetic joints due to the presence of particulate polymer debris found within fibrous tissue, macrophages and foreign body cells. Horowitz et $a l^{25}$ described in an in vitro study that exposure to polymethylmethacrylate (PMMA) particles inhibits macrophage DNA synthesis, impairs their cytotoxic ability and eventually kills the cells. In our study cells that had internalized the lamellar or needle-like PLLA particles showed signs of mild cell damage such as enlarged mitochondria and accumulation of glycogen. Human fibroblasts in culture accumulate glycogen in their cytoplasm as they approach senescence. In the 5.7 year specimens no signs of cell damage were observed. When an implanted material causes cellular damage, an increase in the leakage of intracellular lactate dehydrogenase may be expected. The damaging effect of the PLI.A particles seems to be very low, no increased amounts of mitochondrial LDH could be demonstrated, so it may be assumed that the internalized PLLA crystals do not cause severe cell injury or cell death. The PLLA particles will probably induce a macrophage and fibrocyte response. The time needed for total hydrolytic degradation of the PLLA crystals will probably determine the duration of the swelling.

The results of the trephined bone from the patient with an implantation perind of 5.7 years, show a number of differences compared to the results of subcutaneously implanted material. The degradation of the PLLA screw-thread resembles the degradation of the PLLA bone plate, but the screw remnants are not interlaced with collagen fibres and internalization of PLLA particles by phagocytic cells is very limited. These results may indicate that there can be a variation in the degradation mechanism between subcutaneous and intraosseous PLLA implants and the histological reaction the implant induces. These differences may be explained by the fact that perhaps cortical bone can withstand the osmotic pressure of the degrading material and thus prevent swelling of the PLLA material. The PLLA material remains densely packed which perhaps prevents cellular ingrowth and internalization of PLLA particles.

In summary, the disintegration of PLLA into particles with the accompanying increase in volume of the PLLA material itself and the fibrous tissue, may explain the origin of the described swelling. The PLLA particles with a very slow hydrolytic degradation rate, although not very irritable to the cell, do induce a cellular reaction. These are processes that resemble those seen in aseptic bone loosening in orthopaedic applications. The biocompatibility of the non-degraded PLLA material has been established in a number of studies. The degraded PLLA particles do not cause major ccll injury but they can induce and maintain a clinically detectable swelling which could imply that these PLLA particles can no longer be considered to be fully biocompatible. Future research has to focus on biodegradable polymers that do not disintegrate into highly crystalline particles to avoid very long degradation periods, and in some applications a clinically detectable swelling.

\section{REFERENCES}

1 Akeson WH, Woo SL-Y, Coutts RD, Matthews IV, Gonsalves M, Amiel D. Quantitative histological evaluation of early fracture healing of cortical bones immobilized by stainless steel and composite plates. Calcif Tiss Res 1975; 19: 27-37.

2 Paavolainen P, Karaharju E, Slatis P, Ahonen J, Holmstorm T. Effect of rigid plate fixation on structure and mineral content of cortical bone. Clin Orthop Rel Res 1987; 136: 287-293.

3 Simon BR, Woo SL-Y, McCarthy M, Lee S, Akeson WH. Parametric study of bone remodeling beneath internal fixation plates of varying stiffness. J Bioeng 1978; 2: 543-556.

4 Tunc DC, Rohovsky MW, Lehman WB, Strongwater A, Kummer F. Evaluation of body absorbable bone fixation devices. Proc 31st Ann Orthop Soc, Las Vegas, Jan 1985: 165. 
5 Christel P, Vert M, Chabot F, Abols Y, Leray JL. Polylactic acid for intramedullary plugging. In: Advances in Biomaterials Vol. 5 (ed Ducheyne P). Amsterdam: Elsevier Science; 1984: 1-6.

6 Vert M, Christel P, Chabot F, Leray J. Bioresorbable plastic materials for bone surgery. In: Macromolecular Biomaterials, (eds Hastings GW, Ducheyne P). Boca Raton, FL: CRC Press; 1984: 120-142.

7 Böstman $O$, Mäkelä EA, Tömälä $P$, Rokkanen $P$. Transphyseal fracture fixation using biodegradable pins in children. J Bone Joint Surg $[B r]$ 1989; 17-B: 706707.

8 Suuronen R. Comparison of absorbable self-reinforced poly-L-lactide screws and metallic screws in the fixation of mandibular condyle osteotomies: An experimental study in sheep. $J$ Oral Maxillofac Surg 1991; 49: 989-995.

9 Leenslag JW, Pennings AJ, Bos RRM, Rozema FR, Boering G. Resorbable materials of poly(L-lactide). VI. Plales and screws for internal fracture fixation. Biomaterials 1987; 8: 70-73.

10 Gogolewski S, Pennings AJ. Resorbable materials of poly(L-lactide) 2. Fibers spun from solutions of poly(Llactide) in good solvents. I Appl Polym Sci 1983, 28: 104b-1061.

11 Gogolewski S, Pennings AJ. Resorbable materials of poly(L-lactide). 3. Porous materials for medical application. Colloid Sci 1983; 261: 477-484.

12 Leenslag JW, Gogolewski S, Pennings AJ. Resorbable materials of poly(L-lactide). 5. Influence of secondary structure on the mechanical properties and hydrolyzability of poly(L-lactide) fibers produced by a dryspinning method. J Appl Polym Sci 1984; 29: 2829-2842.

13 Bos RRM, Rozema FR, Boering G, Nijenhuis AI, Pennings AJ, Verwey AB. Bioabsorbable plates and screws for internal fixation of mandibular fractures. A study in six dogs. Int J Oral Maxillofac Surg 1989; 18: 365-369.

14 Bos RRM, Rozema FR, Boering G, Nijenhuis AJ, Pennings AJ, Jansen HWB. Bone plates and screws of bioabsorbable poly(L-lactide). An animal pilot study. $B r$ J Oral Maxillofac Surg 1989; 27: 467 476.

15 Rozema FR, Bos RRM, Pennings AJ, Jansen HWB. Poly(L-lactide) implants in repair of defects of the orbital floor. An animal study. J Oral Maxillofac Surg 1990; 4B: 1305-1309.
16 Bos RRM, Rozema FR, Boering G et al. Degradation of and tissue reaction to biodegradable poly(L-lactide) for use as internal fixation of fractures. A study in rats. Biomaterials 1991; 12: 32-36.

17 Bos RRM, Rozema FR, Boering G, Nijenhuis AJ, Pennings AI, Verwey AB. Resorbable poly(L-lactide) plates and screws for the fixation of unstable zygomatic fractures. J Oral Maxillofac Surg 1987; 45: $751-753$.

18 Rozema FR de Bruijn WC, Bos RRM, Boering G, Nijenhuis AJ, Pennings AJ. Late tissue response to bone-plates and screws of poly(L-lactide) used for fracture fixation of the zygomatic bone. In: Doherty PJ, Williams RL, Williams DF, eds, Biomaterial - Tissue Interfaces, Advances in Biomaterials vol. 10. Amsterdam: Elsevier, 1992: 349-355.

19 Bergsma JE, Rozema FR, Bos RRM, de Bruijn WC. Foreign body reactions to resorbable poly(L-lactide) bone plates and screws used for the fixation of unstable zygomatic fractures. I Oral Maxillofac Surg 1993; 51: 666-670.

20 Hulstaert CE, Kalicharan D, Hardonk MJ. Cytochemical demonstration of phophatases in the rat liver by a cerium-based method in combination with osmiumtetroxide and potassium ferrocyanide post-fixation. Histochemistry 1983; 78: 71-79.

21 Hanker JS, Kusyk CJ, Bloom FE. The demonstration of dehydrogenases and monoamine oxidase by the formation of osmium blacks at the sites of Hatchett's brown. Histochemie 1973; 33: 205-230.

22 Böstman O, Päivärinta U, Manninen M, Rokkanen P. Polymeric dehris from ahsorhahle polyglycolide screws and pins. Acta Orthop Scand 1992; 63: 555559.

23 Fornasier V, Wright J, Seligman J. The histomorphologic and morphometric study of asymptomatic hip arthroplasty. A postmortem study. Clin Orthop 1991; 271: 272-282.

24 Dolwick MF, Aufdemorte TB. Silicone-induced foreign body reaction and lymphadenopathy after temperomandibular joint arthroplasty. Oral Surg Oral Med Oral Pathol 1985; 59: 449-452.

25 Horowitz SM, Gautsch TL, Frondoza CG, Riley Jr L. Macrophage exposure to polymethyl methacrylate leads to mediator release and injury. $J$ Orthop Res 1991; 9: 406-413. 